\title{
A Acumulação Produtiva no Capitalismo Contemporâneo
}

Productive accumulation and the contemporary capitalism

\author{
JOSÉ RICARDO TAUILE* \\ LUIZ AUGUSTO ESTRELLA FARIA**
}

\begin{abstract}
"In the labor of engines and trades and the labor of fields I find the developments, and find the eternal meanings.”(Walt Withman)
\end{abstract}

RESUMO: A virtualidade, a imaterialidade e o desenvolvimento de formas ainda mais abstratas de riqueza são características do capitalismo contemporâneo. No entanto, o curso da acumulação requer trabalho produtivo. As transformações ocultas sob essas formas de aparência são vistas à luz do pensamento de Marx de três maneiras diferentes. 1. As novas formas de trabalho produtivo que desafiam a distinção de produtivo e improdutivo. 2. A transformação do capital produtivo através da concentração, centralização e mudança de formas de concorrência. 3. A relação entre capital produtivo e capital financeiro e o novo papel do capital monetário.

PALAVRAS-CHAVE: Capitalismo contemporâneo; capital financeiro; capital produtivo; dinheiro e trabalho produtivo.

ABSTRACT: Virtuality, immateriality and the development of even more abstract forms of wealth are characteristics of contemporary capitalism. Nevertheless, the course of accumulation needs productive labor. The transformations hidden under these appearance forms are viewed in the light of Marx's thought in three different ways. 1. The new forms of productive labor that challenge the distinction of productive and unproductive. 2. The transformation of productive capital through concentration, centralization and changing forms of competition. 3 . The relationship of productive capital and finance capital, and the new role of money capital. KEYWORDS: Contemporary capitalism; finance capital; productive capital; money and productive labour.

JEL Classification: F63; N10; P16.

* Instituto de Economia da Universidade Federal do Rio de Janeiro - UFRJ, Rio de Janeiro/RJ, Brasil. E-mail: tauile@ie.ufrj.br.

* Universidade Federal do Rio Grande do Sul - UFRGS, Porto Alegre/RS, Brasil. E-mail: lufaria@ ufrgs.br. Submetido: agosto 2002; aceito: maio 2003. 
As transformações do capitalismo contemporâneo têm chamado a atenção por sua virtualidade, imaterialidade e pelo desenvolvimento de formas cada vez mais abstratas de riqueza. Essa realidade faz parecer que, ao contrário do que pensavam os economistas clássicos, a criação de valor prescinde da produção e do trabalho. Mais ainda, no campo da economia política de inspiração marxista ou heterodoxa, o inchaço do capital financeiro (Tauile e Faria, 1999) que se verificou após a crise dos anos 70 levou alguns autores a vislumbrar a inauguração de um novo regime de acumulação em escala internacional, caracterizado por uma dominância financeira (Chesnais, 1997b).

Em nossa maneira de ver, muitos dos pressupostos de um novo regime de acumulação podem ser vislumbrados na onda de inovações em curso, nas transformações no mundo do trabalho e da produção, nas mudanças institucionais em curso. Entretanto, no que respeita à dominância financeira, nossa posição segue os passos de Braudel (1979) e Arrighi (1994), que apontam, não para uma nova forma da acumulação capitalista, mas sim para uma fase de declínio e transição da etapa anterior, caracterizada por uma hegemonia necessariamente temporária da forma dinheiro e da fração financeira da classe burguesa e que sempre veio acompanhada por um aumento da instabilidade do sistema. O retorno a um caminho sustentado do movimento de acumulação de capital só pode ter lugar após o declínio dessa hegemonia e apenas a partir disso se abre a possibilidade de um novo estágio de desenvolvimento, em um novo regime de acumulação, com o centro do poder econômico retornando à esfera da produção.

A visão de Marx sobre as crises capitalistas tinha essa mesma perspectiva. Em diversas passagens, mas de forma mais sistemática no livro III de O Capital e nas Teorias da Mais-Valia, ele interpretou as conjunturas de expansão dos negócios financeiros, sempre acompanhadas de um surto de especulação nas bolsas de valores e demais mercados de títulos e haveres, como manifestações de uma perda de dinâmica e de uma crise que se vinham gestando na esfera da produção. Central em seu argumento foi o desenvolvimento do conceito de capital fictício (Marx, 1863 e 1890).

Neste trabalho pretendemos, à luz de Marx, examinar a acumulação produtiva, as mudanças no mundo do trabalho, nos processos de produção e no comportamento do capital na forma produtiva que dá origem a essa realidade na atual cena internacional. Com isso pretendemos lançar alguma luz para compreender o real significado desse inchaço do capital financeiro e qual sua influência sobre o mundo do trabalho e da produção. Isso será feito nas três seções a seguir. Na primeira, as transformações nas relações de produção serão examinadas para identificar até que ponto implicam novas fronteiras delimitadoras da distinção entre trabalho produtivo e improdutivo. Além disso, na medida em que a desregulação do mercado de trabalho propicia a instituição de novas formas de assalariamento (cooperativas, autogestão, pequena produção), com efeitos sobre a distribuição da renda e a concorrência capitalista, será discutida a influência desses processos sobre o desenvolvimento capitalista.

Numa segunda seção, o foco é a importância do capital produtivo como agen- 
te coletivo da produção de riqueza. As transformações do capital produtivo, no seio das quais novas formas de concorrência vêm se desenvolvendo por meio do aprofundamento dos processos de centralização e concentração do capital, serão consideradas. Produtivo e improdutivo serão estendidos, considerando segmentos inteiros da atividade econômica. A propósito, discute-se brevemente o que é a natureza das mercadorias (e da riqueza) no capitalismo contemporâneo.

Finalmente, examinamos a relação entre capital produtivo e capital fictício. A globalização, como outras vezes na história, trouxe um inchaço do capital financeiro, um enorme aumento do volume de capital fictício em circulação e um balançar do pêndulo do poder econômico do capital produtivo para o dinheiro. A redistribuição da mais-valia, tanto da parcela gerada na esfera da produção, quanto a apropriada pelo Estado como imposto, ganha um enorme significado na forma de juros e rendimentos financeiros. Nesse processo, o próprio sistema de preços é modificado, pois, além de alcançar uma dimensão crescentemente internacionalizada, passa a responder às forças que impulsionam essa redistribuição, acirrando o conflito entre a valorização pelo trabalho produtivo e as rendas de monopólio. Dois mecanismos de apropriação da mais-valia se põem em marcha; um privado, acionado pelos novos mecanismos de concorrência e novas formas de articulação entre empresas, e um social, impulsionado pela nova relação criada entre o sistema financeiro, o Estado e as relações internacionais.

\section{AS NOVAS FORMAS CONCRETAS DO TRABALHO PRODUTIVO}

A definição do que é ou não trabalho produtivo no capitalismo não é meramente uma questão histórica que diga respeito estritamente à época de constituição do capitalismo produtivo, isto é, ao ingresso do capital na esfera da produção por meio, sucessivamente, da subsunção formal e real do trabalho. Ela permanece ainda bastante importante para delinear os fatores que efetivamente alavancam o processo de acumulação capitalista. especialmente em tempos de revolução tecnológica. Se entendermos onde se localiza ou para que âmbito conflui o trabalho produtivo, teremos uma noção mais precisa da fonte da geração do excedente e, conseqüentemente, da lógica que norteia esse processo de acumulação social de riqueza sob um modo capitalista.

Desde o processo de formação do capitalismo produtivo, o trabalho - e especialmente o trabalho produtivo - é reconhecido, do ponto de vista da teoria marxista, como o principal responsável pela agregação de valor e pela produção de valor excedente. Se, na melhor tradição, essa assertiva ainda pode ser considerada válida, ${ }^{1}$ cabe então definir qual tipo de trabalho enquadra-se nela, especialmente dado que o

\footnotetext{
${ }^{1}$ Segundo Chilcote (1997), entre $85 \%$ e $90 \%$ dos preços industriais relativos nos países da OECD, desde o pós-guerra, ainda seriam explicados pelo tempo de trabalho relativo - direto e indireto - incorporado nas respectivas mercadorias.
} 
capitalismo é multiforme, evolui com o tempo e com a história, e passa por profundas e qualitativas transformações a cada revolução tecnológica, como a revolução mercantil, a revolução industrial e agora a revolução da informação. As formas fenomênicas do trabalho produtivo - aquele responsável pela geração do valor excedente e que dá o padrão das relações sociais característico da natureza do sistema — também evoluem, portanto, de maneira multiforme. Assim, dizer como diz Marx no capítulo de O Capital sobre processo de trabalho, que qualquer trabalho que produza alguma coisa é produtivo não ajuda em nada a entender a dinâmica da acumulação capitalista, como ele próprio ressalta em uma importante nota de rodapé daquele capítulo (Marx, 1863, Capítulo V). Esta é uma questão fundamental para seu arcabouço teórico, pois lida conceitualmente com o principal elemento gerador de excedente nesse modo de produzir socialmente e a maneira como ele se reproduz.

Tomemos então a questão do trabalho produtivo, no âmbito do capitalismo produtivo, que se originou progressivamente a partir do "capitalismo mercantil". Algumas perguntas simples podem ajudar a esclarecer a natureza complexa dessa questão. Quem deve ser considerado trabalhador produtivo no capitalismo e por quê? E ele é produtivo para quem e a partir de quais referências?

Para que o trabalho seja considerado produtivo, no capitalismo, é preciso que atenda a duas condições necessárias: que seja assalariado, isto é, que esteja subsumido nas relações sociais de produção capitalistas, e que esteja inserido especificamente na esfera da produção, ou seja, que produza, não apenas valor, mas valor excedente. ${ }^{2}$ É preciso que produza não só excedente, mas também as relações sociais nas quais está inserido. ${ }^{3}$

O primeiro suposto implica que o trabalhador/empresário autônomo (uma costureira, como no exemplo de Marx, ou um programador, para atualizá-lo) não é considerado produtivo porque, apesar de produzir mercadorias, não o faz sob uma forma que reproduza as relações de produção especificamente capitalistas, ou seja, por meio do assalariamento. Portanto, se o mesmo trabalhador fosse empregado de uma empresa (de confecção ou de uma software house, neste exemplo), passaria, então, a ser considerado produtivo não só porque produz o valor excedente apropriado pelo empresário que o emprega, como porque, ao receber um salário como pagamento pelo desempenho de sua capacidade de trabalho, reproduz as relações sociais de produção que permitem essa apropriação.

Olhando pelo lado técnico, conforme visto em Tauile (2001), e tomando como referência uma unidade de acumulação individualmente (uma empresa), o trabalho produtivo é todo aquele que tenha alguma responsabilidade técnica sobre a con-

\footnotetext{
${ }^{2}$ A distinção entre valor de uso e valor de troca é uma outra forma de ver a conceituação de trabalho produtivo. Muitas formas de trabalho, a exemplo da costureira de Marx, geram valor de uso sem valor de troca, assim como alguns produtos do trabalho, mesmo que tenham valor de troca, como o repolho de um camponês na feira, não são uma criação do trabalho produtivo na medida em que, no seu preço, não não há excedente ou mais-valia (ver também Tauile, 2001, cap. 2).
}

${ }^{3}$ Aprofundando a subsunção do trabalho ao capital. 
fecção do produto final e sua colocação à disposição dos consumidores nos respectivos mercados. Desse modo, é importante desde logo romper com a idéia de que a "esfera da produção" se restringe ao chão de fábrica. Ela de fato inclui, e cada vez mais, inúmeras atividades realizadas nos escritórios, como, por exemplo, operar papéis ou meios magnéticos (entre outras), à medida que se amplia e se difunde a automação da produção stricto sensu. Aliás, o respectivo produto pode nem se constituir em um bem material, estrito senso; pode tratar-se de um serviço (seja ele um serviço tradicional ou realizado por meio de um ambiente cibernético virtual). De qualquer modo, nela devem estar incluídas atividades que vão desde as dos trabalhadores responsáveis pelo seu projeto ${ }^{4}$ até aquelas de transporte do produto para o local do mercado, passando por diversas outras, como as de manufatura (se for o caso de um produto material) e as de estocagem, especialmente quando a mercadoria em questão estiver sujeita a problemas de sazonalidade. ${ }^{5}$

Similarmente, atividades que, apesar de assalariadas, estejam localizadas na esfera da circulação, tais como de financiamento, compras, vendas etc., ou ainda que sejam contratadas diretamente pelo consumidor final, como no caso de serviços pessoais, não devem ser consideradas produtivas, de maneira geral. Apesar do trabalho excedente, não há geração de valor excedente.

A distinção feita por Marx entre trabalho produtivo e improdutivo encontra notável correspondência com a distinção que os próprios empresários fazem entre trabalho como custo (produtivo) e como despesa (improdutivo). ${ }^{6} \mathrm{Ou}$ seja, sob qualquer ponto de vista - teórico ou empresarial —, o trabalho improdutivo deve ser considerado uma dedução do excedente gerado pelo trabalho produtivo.

Outro aspecto importante a enfatizar diz respeito à própria natureza das mercadorias. Não importa que elas sejam de natureza material ou imaterial, em outras palavras, não importa que sejam um bem físico (real ou virtual) ou um serviço prestado. Mas, para ser produtivo, é fundamental que o trabalho esteja inserido na esfera da produção ${ }^{7}$ desse bem e que seja subsumido na sua relação com o capital por meio do assalariamento.

Importa, isto sim, identificar as atividades produtivas que concentram maior valor na sua qualificação (formação/custo de reprodução social) e, logo, produzem proporcionalmente mais valor adicionado. Com a inexorável tendência à divisão do trabalho capitalista, ${ }^{8}$ observa-se uma incessante simplificação e conseqüente

\footnotetext{
${ }^{4}$ Até mesmo atividades ligadas à definição prévia de como deve ser o produto devem estar aí incluídas.

${ }^{5}$ Vale notar, a título de esclarecimento: as atividades de estocagem relativas à especulação não devem ser consideradas produtivas dado que não alteram nenhuma característica do produto final, seja de forma, seja de conteúdo, não alterando, pois, também a natureza concreta do consumo.

${ }^{6}$ Shane Mage (1963) mostrou que isso era especialmente verdade em relação aos empresários norteamericanos.

${ }^{7}$ Ainda que, como foi dito acima, usando-se um conceito de produção não restrito ao chão de fábrica.

${ }^{8}$ Tarefas diferentes atribuídas a pessoas diferentes separadas hierarquicamente entre aquelas que as concebem/projetam ou as administram e aquelas que as executam.
} 
desvalorização das atividades "finais" dos processos produtivos, isto é, do trabalho vivo neles localizados. Conforme descrito em O Capital (Marx, 1867), e retomado em Tauile (2001), à medida que as tarefas de execução foram sendo simplificadas e tornadas repetitivas, foi se tornando possível materializar a inteligência a elas correspondente, em equipamentos com a forma social de capital fixo. Conseqüentemente, a operação desses equipamentos de produção - de produtos padronizados, em alta escala por meio de automação rígida — passaram a exigir atividades mais especializadas (menos qualificadas no sentido geral) ${ }^{9}$. Esse padrão, típico da Revolução Industrial, não se esgotou aí, reproduzindo-se ainda hoje com a revolução da informação: equipamentos mais inteligentes tornados user friendly permitem usuários "burros". Assim, de maneira geral, mas principalmente quando se trata de tarefas simples e repetitivas, o padrão de trabalho exigido nas tarefas de execução (e na medida em que não seja ainda automatizado) tende a ser cada vez mais simples e desvalorizado. Logo, ainda que produtivas, essas formas de trabalho tendem também a incorporar pouco, e cada vez menos, valor aos produtos.

A demanda por melhores qualificações (ainda que diversas e mutantes) tende a reduzir-se relativamente e concentrar-se no âmbito das tarefas de concepção (projeto/design), gerenciamento da produção ou, no chão de fábrica, daquelas ligadas à produção de bens de capital, a atividades de ferramentaria ou ainda alguns serviços de manutenção dos equipamentos e sistemas. Para lá, portanto, migram as atividades mais produtivas, (por serem) as que mais adicionam valor. ${ }^{10}$ Essas atividades permanecem estratégicas para o processo de produção como um todo, dado que concentram a inteligência ou as informações de como e por que fazer. As qualificações ainda necessárias a tais atividades, e sua capacidade de irradiar/multiplicar seu efeito bem como de alavancar transformações através do circuito de acumulação e até mesmo da cadeia produtiva, fazem com que elas, apesar de relativamente reduzidas ${ }^{11}$ (repetimos), permaneçam especialmente valorizadas mesmo no capitalismo contemporâneo.

Ressalta-se assim, e especialmente diante da natureza mutante do capitalismo contemporâneo, a importância estratégica das atividades ligadas ao conhecimento produtivo (know-how, know-why), estejam elas na fase da ciência experimental ou propriamente caracterizadas como tecnologias de produto ou de processo. São essas atividades que mais geram valor e mais valor. A rigor, poder-se-ia dizer então que delas provêm as maiores taxas de extração do excedente, a sustentar a dinâmica do novo padrão de acumulação.

Porém, a esse pólo cada vez mais valorizado, que, como acabamos de ver, cada vez mais concentra de maneira restrita o trabalho produtivo, contrapõe-se um

\footnotetext{
${ }^{9}$ Não se deve tomar o conceito de especialização — que vem de "especial" - como sinônimo de qualificação, mais ligado à noção de geral. Ao contrário, em muitos casos pode-se dizer que se movem em sentidos contrários.

${ }^{10}$ A esse respeito, ver, por exemplo, Morris-Suzuki (1997).

${ }^{11}$ Relativamente, em termos do correspondente volume de emprego.
} 
amplo leque de desvalorização do trabalho, devido à sua simplificação — à "abstratificação" do trabalho concreto (Taule e Faria, 1999) — e à desregulamentação das condições de exercício de suas atividades profissionais. É nesse amplo âmbito de turbulências que se manifestam de maneira mais nítida e violenta a degradação coletiva do trabalho e as crises do capitalismo contemporâneo.

Desse caldo de instabilidade e deterioração das condições de reprodução social, surgem reações espontâneas de parcelas da população produtiva que se organizam sob formas diversas de economia solidária. Pequena produção informal e cooperativas - autogestionárias ou não - são exemplos de reação de parte dessa população perdedora e excluída, em busca do provimento mínimo de renda necessária para seu sustento e de seus dependentes, pelo menos em um primeiro momento. Todavia, mesmo que no longo prazo seus objetivos sejam os mais nobres possíveis e as relações de trabalho, bastante democratizadas, é quase inevitável que, no curto prazo, os circuitos do capital social global, nos quais estão incluídos esses empreendimentos solidários, aproveitem-se de sua relativa fragilidade e da ausência de um empresário capitalista individual que intermedeie a ligação com os produtores diretos, para auferir ganhos extraordinários. Em muitos casos, apesar de não haver a figura da mais-valia no interior do empreendimento solidário em si, as grandes empresas capitalistas contratantes de seus serviços, muitas vezes sob a forma de verdadeiros monopsônios, apropriam-se de um valor excedente adicional equivalente àquele que seria apropriado por um empresário dessa atividade caso ela fosse organizada de maneira tradicional.

Como se pode perceber, esta discussão sobre trabalho produtivo - e, $\operatorname{logo}$ a seguir, sobre capital produtivo - é vital para entender os mecanismos da produção de excedente no âmbito do capitalismo, sempre sujeito a mutações (incessantes) nas suas formas de acumulação. Em cada etapa de evolução do capitalismo, quem é, ou melhor, que agentes são responsáveis pela dinâmica de acumulação da riqueza social e por quê? A questão permanece atual, especialmente no que concerne à dinâmica de reprodução do capitalismo contemporâneo. Ao longo da constituição do capitalismo moderno, o típico trabalhador produtivo localizava-se em uma grande fábrica, por exemplo, em uma linha de montagem, e o valor que agregava ao produto era razoavelmente coerente com o tempo de trabalho socialmente dedicado à confecção do produto. Porém, no capitalismo contemporâneo, o valor agregado ou transferido não parece ser balizado pelo tempo do trabalhador diante de uma tela de controle ou do teclado de um micro. Muitas vezes, o trabalho intelectual voltado para a concepção criativa não parece ter uma vinculação significativa com o tempo de atividade (de trabalho) em si. Em vez de sua importância estar vinculada ao tempo de trabalho gasto, seria mais relevante, então, dar conta dos efeitos de alavancagem que desencadeia. ${ }^{12}$

Mesmo mantendo rigorosamente a abordagem de Marx sobre a formação do

\footnotetext{
12 Poder-se-ia mesmo argumentar, tentativamente, que seria o caso de fazer ressurgir a clássica questão sobre a fonte do valor das mercadorias, entre trabalho incorporado e trabalho comandado.
} 
valor das mercadorias, há que se reconhecer as enormes quantidades de conhecimento do trabalhador incorporado nos equipamentos e meios de produção em geral, sob a forma de capital constante (fixo e circulante) e que, por mais que o trabalho pretérito tenha sido desvalorizado por não ser mais socialmente necessário, implica uma razão excessivamente alta entre este C (capital constante) e o fundo de salários necessários para pagar os trabalhadores que o operam, isto é, V (capital variável). Essa desproporção teria ficado subitamente agravada com o advento de uma nova revolução tecnológica que ampliou os limites da automação, tornandoa flexível e afeita também à produção em baixa escala. Isto para não falar nas especificidades distintas das mercadorias características dessa nova base técnica. Espaços de acumulação de natureza qualitativamente nova são abertos pelas tecnologias digitais de tratamento e transporte de informações, especialmente claros quando configuram espaços cibernéticos "virtuais". Ampliações drásticas das possibilidades de interação social que se estabelecem entre os membros da espécie humana implicam necessariamente a atualização da percepção do que seja produção social, incluso aí o próprio processo de valorização das atividades humanas e dos produtos de seu trabalho. ${ }^{13} \mathrm{~A}$ questão da propriedade intelectual, como aquelas ligadas à tecnologia da saúde em senso largo (biotecnologias, tecnologias moleculares, ambientais etc), recoloca, num nanoescopo o binômio trabalho/renda.

Estaria a atual revolução tecnológica ${ }^{14}$ sendo veículo de uma nova etapa do desenvolvimento capitalista em que a importância da informação comandada sobrepuja o tempo de trabalho incorporado na formação dos elementos do valor? Para se poder responder devidamente a essa questão é necessário inquirir sobre a natureza da acumulação contemporânea começando, portanto, pela natureza da mercadoria e, logo, pela discussão do que seja riqueza.

Será o conceito de desenvolvimento capitalista hoje em dia uma questão que diga respeito ao incremento da riqueza material ou trata-se também (e, talvez, principalmente) da difusão e do aprofundamento das relações sociais capitalistas? Se a resposta é "ambos", como balancear sua incidência? Deve-se considerar essencialmente estoques físicos, materiais ou devemos falar inclusive de relações sociais que propiciam direitos de acesso a privilégios? A posse e a respectiva propriedade privada de bens materiais tornava essa questão mais clara (ou menos controversa) no âmbito do (moderno) capitalismo industrial. Porém, se estamos falando de direito de acesso a privilégios, quem os garante? Por que respeitar os contratos? Em muitos casos, tais acessos são viabilizados por construtos materiais, porém, em outros tantos, estão consubstanciados em convenções sociais de uma ordem política. Afinal, o rei é rei porque seus súditos o reconhecem como tal. Se há uma aparente desconexão entre o valor e sua produção real/concreta, a teoria do valor

\footnotetext{
${ }^{13}$ A propósito, aqui seria relevante rediscutir sob que condições uma atividade configura um trabalho propriamente dito.

${ }^{14}$ Por meio da difusão da automação flexível e da criação de novos espaços virtuais (cibernéticos) de acumulação (real), entre outros elementos.
} 
do trabalho no capitalismo contemporâneo deve ser reconsiderada. Deve ela ser entendida como uma teoria do esforço e do sacrifício ("the toil and trouble...”), do tempo (socialmente necessário), ou da inteligência do trabalho (capacidade de alavancagem de transformações a jusante de sua execução), ou dos três (e, neste caso, em que proporção) ${ }^{15} \mathrm{O}$ trabalho considerado deve ser estritamente o individual ou devese levar em conta seu alcance coletivo, sua dimensão social. ${ }^{16}$

Como um corolário desta discussão, caberia indagar se a forma assalariamento continua a ser uma condição necessária para que um trabalho seja considerado como produtivo. Em outras palavras, qual será o papel do trabalho assalariado para a acumulação capitalista contemporânea. De que tipo e em que proporções. Mas, afinal, voltamos à questão: o que se deve entender por trabalho?

\section{AS TRANSFORMAÇÕES DO CAPITAL PRODUTIVO E O SEU PAPEL NA GERAÇÃO DA RIQUEZA}

Um outro ponto de vista para se analisar o que é produtivo ou não (produtivo de riqueza e de excedente econômico), seria tomar como referência o capital social como um todo. Entender sob essa ótica não só o papel do trabalho, mas também do capital, como agente da produção e reprodução do capital social como um todo, pode ajudar a caracterizar o grau de desenvolvimento capitalista da economia em questão. Neste caso, porém, e desde logo, a questão complica-se um pouco. Para equacioná-la de maneira devida, caberia identificar, de início, quais setores contribuiriam, ou não, efetivamente para a "riqueza — capitalista — da nação" ou da economia. Quais capitais ou setores como um todo são produtivos, no sentido de geradores de valor, e quais são apenas "co-usufrutuários da mais valia", como observa Marx no "capítulo inédito" (Marx, 1864)?

Sob essa ótica, todos os setores característicos da esfera da circulação, como o bancário ou o de vendas, não deveriam ser considerados produtivos, pois sua contribuição para o produto social é meramente contábil. Quando muito, sua existência indica a difusão das relações sociais de produção capitalista; sua representação na contabilidade nacional seria, então, uma medida da transformação do modo de produção. Sua contribuição real para a riqueza social pode ser interpretada como negativa na medida em que, como o trabalho improdutivo em si, tais segmentos - improdutivos - constituem-se em uma dedução do excedente econômico global e vivem exclusivamente da apropriação de partes desse excedente, gerado por outros segmentos (produtivos). De fato muitos desses segmentos, bem como uma série de atividades-chave que os constituem, existem apenas para viabi-

\footnotetext{
${ }^{15}$ Uma coisa é certa, mesmo atualizando as concepções marxistas, a teoria do valor do trabalho não parece mais ser um pilar adequado (e suficiente) à luta de classes.

${ }^{16}$ Novamente aqui cabe uma reflexão sobre essa questão, que é semelhante à do trabalho comandado.
} 
lizar a forma social de produção e distribuição/apropriação do excedente (da riqueza) vigente naquela etapa do desenvolvimento capitalista.

Não obstante essas considerações, atividades dentro desses segmentos considerados "improdutivos" numa perspectiva mais abrangente, de um ponto de vista "macro", podem ser consideradas produtivas para empreendedores capitalistas individualmente que ocupem, de um ponto de vista "microeconômico", os espaços de acumulação inerentes a esses segmentos. Repetimos, entretanto, que, sob a ótica do capital social como um todo, tais empreendedores só acumulam porque a maisvalia, da qual se apropriam e que suas empresas supostamente geram de maneira individual, na verdade lhes é repassada globalmente por empreendedores no âmbito de segmentos produtivos. Novamente, tais capitais produtivos necessitam de determinados serviços improdutivos, ou de seus produtos, devido à especificidade capitalista dos respectivos processos de circulação de mercadorias, e não por uma necessidade técnica de o produto ter o valor de uso que tem e/ou estar disponível para consumo no seu mercado.

Vale destacar também que, nesse mesmo Capítulo VI, inédito, Marx recupera parcialmente algo que parece ser uma das principais lacunas de seu arcabouço teórico: a valorização da atividade do empreendedor:

"O capitalista, como representante do capital que entra no seu processo de valorização, do capital produtivo, desempenha uma função produtiva que consiste precisamente em dirigir e explorar o trabalho produtivo. Contrariamente aos co-usufrutuários da mais-valia que não se encontram em tal relação direta com a sua produção, a classe do capitalista é a classe produtiva por excelência (par excellence. Fr.). (Como condutor do processo de trabalho, o capitalista pode executar trabalho produtivo no sentido em que o seu trabalho se integrar no processo de trabalho coletivo objetivado no produto.)" (Marx, 1864).

Há, assim, um reconhecimento claro de que a concepção, a organização e o comando do processo de produção capitalista considerado podem constituir atividades produtivas de riqueza social e que incluam o empresário em si. Novamente, porém agora em virtude da própria mudança da base técnica, retorna a discussão sobre o que seja uma mercadoria ${ }^{17}$ e o que se deve entender por riqueza. $\mathrm{Na}$ primeira frase do primeiro capítulo de O Capital, Marx fala de uma "imensa acumulação de mercadorias", de "coisas"..., ou seja, implica a noção de estoque. Entretanto, mais adiante, no próprio O Capital e em outros escritos, Marx frisa que atividades de serviço podem ser vendidas como mercadorias, ainda que, adicionamos, estas impliquem a noção de fluxo. ${ }^{18}$ Afinal, se o serviço é um fluxo, suposta-

\footnotetext{
${ }^{17}$ Ver, por exemplo, Tauile et alii, (2001).

18 Ademais, aqui cabe distinguir essas atividades dos chamados "serviços financeiros" associados a formas fictícias de riqueza, como será visto na seção seguinte.
} 
mente não é acumulável. Não obstante, gera direitos (claims) por meio, por exemplo, da captação do equivalente geral (sob a forma de dinheiro ou de títulos), este sim acumulável.

A acumulação capitalista contemporânea, ao difundir a nova base técnica, por força das incessantes batalhas da concorrência, agrava duplamente essa dicotomia, pois tanto promove a automação por meios materiais (e cibernéticos) de um conjunto crescente de serviços (especialmente aqueles ligados ao tratamento padronizado de informações), como, adicionalmente, amplia súbita e enormemente o espectro das atividades classificáveis como serviços que se dão agora por meio da constituição de redes com acesso por parte de grandes massas de consumidores. Referimo-nos aqui não só a redes que operam serviços típicos da Revolução Industrial, mas, agora de maneira e em escala diferentes, àquelas de produtos/serviços até então inexistentes, como as viabilizadas por meio de cabos de fibras óticas, lógicas binárias, terminais de vídeo digitais e sensores, os mais diversos, que simulam realidades virtuais.

Se as redes em si constituem riqueza material, os serviços por elas prestados configuram-se como uma evolução determinada no âmbito das possibilidades de apreensão da natureza, em sentido estrito, e de articulação entre os agentes sociais e econômicos, ou seja da forma como se dá essa apropriação do meio ambiente. O pagamento pelo serviço efetua uma transferência de direitos de acesso ao excedente econômico global. ${ }^{19}$ Configura também o direito de usufruto de um padrão determinado (e eventualmente novo) de "bem-estar", de comportamento, de lazer, de acesso a determinadas "realidades".

Para concluir esta segunda seção, caberia ainda fazer referência ao escopo das batalhas da concorrência capitalista em todas as suas dimensões. Não é mais apenas o capital que, como na origem, disputa com o trabalho a apropriação do excedente ou então, a partir desta disputa, batalha para reduzir custos e conquistar mercados. Também não se restringe a concorrência a confrontar capitais no interior de segmentos econômicos bem delimitados ou que a eles transcendam na busca por produtos novos e de qualidades distintas, materiais ou imateriais. Como sempre, formas renovadas de organização social e institucional da produção, que vão desde a instituição de redes de empresas consorciadas e de linhas "enxutas" de montagem em múltiplas fábricas de dimensão multinacional até relações entre grandes corporações e fornecedores não tipicamente capitalistas, propiciam a apropriação de partes crescentes da mais-valia das cadeias produtivas pelos capitais hegemônicos, que arbitram a divisão do excedente em seu favor. Decidem sobre a remuneração de seus empreendimentos associados, seja de pequenas e médias empresas, seja de empreendimentos "não capitalistas" esquivando-se, no caso, da tendência à equalização da taxa de lucro, a qual passa a ocorrer cada vez mais em escala mundial. Porém, a guerra da concorrência agiganta-se e complexifica-se, travando-se também entre as formas de capital (mercadoria, dinheiro ou produtivo), com hegemonias

${ }^{19}$ Por que não chamar isso de um "fundo de riqueza"? 
temporárias (ainda que eventualmente de longo prazo) e hierarquização circunstancial de algumas dessas formas. A oposição/dicotomia entre o valor do trabalho, a renda monopólica, a remuneração pelo uso de equivalentes "líquidos", seja sob a forma de dinheiro, seja de direitos criados pelos títulos, fica subsumida no âmbito desse contexto de rivalidades de poder econômico. A próxima seção tratará em mais profundidade deste tema.

À semelhança das perguntas colocadas ao final da primeira seção caberiam outras, agora necessárias para caracterizar o papel atual do capital produtivo na fronteira do desenvolvimento capitalista: de que passa a se alimentar a acumulação contemporânea se ela prescinde, em grande medida, do trabalho e da produção material, em sua concepção tradicional? Esta questão fica ainda mais obscura quando se contrapõe a forma financeira (e "fictícia") do capital à sua forma produtiva (e real). O tema será retomado a seguir.

\section{CAPITAL PRODUTIVO E CAPITAL FICTÍCIO}

As transformações das relações de trabalho e do capital produtivo foram acompanhadas de mudanças significativas na esfera da circulação do valor. As relações monetárias e financeiras, que propiciam a metamorfose do capital e operam essa circulação, também se modificaram profundamente num processo ao qual chamamos inchaço do capital financeiro (Tauile e Faria, 1999), também identificado como financeirização da riqueza.

Uma característica desse inchaço, que tem chamado muito a atenção tanto de pesquisadores quanto da opinião pública, é a centralidade e o comando que as finanças adquiriram sobre a vida econômica, com importantes conseqüências políticas e sociais. As cifras extraordinárias de ganhos, as referências permanentes na imprensa, o notório poder exercido pelos dirigentes de bancos, corretoras ou consultorias de investimento sobre as políticas econômicas e o perceptível encolhimento da atividade produtiva e do emprego, contraposto à exuberância dos fundos financeiros, têm reforçado no senso comum a idéia de que dinheiro cria dinheiro e que sua propriedade é a mais segura fonte de prosperidade no mundo. A avalanche do pensamento único nos meios acadêmicos reforça essa impressão, com o repetir estéril das teorias formuladas originalmente por aqueles a quem Marx chamou economistas vulgares, numa arenga sobre a "produtividade" dos investimentos que só torna mais atual a crítica ao fetichismo da mercadoria.

É evidente, nesta fase da existência do capitalismo, uma aparentemente sólida hegemonia do capital financeiro, que se traduz, no plano macro, em sua influência sobre governos e organismos multilaterais e, no plano micro, numa crescente financeirização ${ }^{20}$ das empresas e até das famílias, inclusive as de estrato de renda

\footnotetext{
${ }^{20}$ Por financeirização no plano micro queremos nos referir ao fato de as aplicações financeiras e sua gestão ocuparem um papel central na esfera econômica da vida. Isso abrange tanto o fenômeno dos
} 
médio ou menos que isso. O crescimento espetacular dos estoques de haveres financeiros - e, dentre estes, das dívidas públicas -, a internacionalização e interconexão dos mercados financeiros, a invenção de novas modalidades de operações nesses mercados, a desregulamentação proporcionando uma ampliação de seu raio de ação sem precedente, o aumento meteórico da velocidade de giro dos "produtos" financeiros, o crescimento da parcela do PIB apropriada como juros e rendimentos de inversões, tudo isso mudou bastante a face do capitalismo na virada do século. $\mathrm{E}$, se a isso associarmos as mudanças nas relações de trabalho e na esfera da produção referida acima, somos levados a refletir sobre a permanência e sustentabilidade dessas transformações.

Alguns autores, a exemplo de Chesnais (1997b), vêem nessa financeirização da economia a inauguração de um novo regime de acumulação. Para Arrighi (1994), trata-se da manifestação de um processo periódico da história do capitalismo, no qual o esgotamento de um ciclo longo de acumulação vem acompanhado do predomínio das finanças em sua fase de declínio, revertido assim que o capital, represado na forma dinheiro, encontre outra vez aplicação na esfera da produção, quando então se inaugura um novo ciclo de expansão sobre novas bases materiais (novos produtos, novos processos, novos mercados).

Uma terceira forma de interpretar essa hegemonia financeira é como manifestação de uma tendência na longa duração do desenvolvimento do modo de produção capitalista, a qual aparece de forma diversa nas diferentes fases de cada ciclo longo de expansão. Na hoje minoritária produção acadêmica heterodoxa do Brasil, país particularmente afetado pela instabilidade financeira contemporânea, não por acaso a reflexão sobre esse fenômeno tem tido um lugar importante (Braga, 1997, Belluzzo, 1999, Tavares e Fiori, 1997). O ponto de partida desse debate é a concepção formulada originalmente por Marx sobre o processo de metamorfose e valorização do capital e a relação que nele tem origem entre capitalistas industriais e banqueiros. A formulação inicial de Marx, tal como aparece na Teoria da Mais-Valia e em O Capital, tem como ponto de partida, de um lado a tendência à concentração e centralização do capital e, de outro, a relação entre moeda e crise.

Quando estudou a relação do capital dinheiro com o capital produtivo, Marx viu o papel da intermediação financeira expandindo a capacidade produtiva por meio do aporte de uma massa maior de meios ao empresário industrial. Em sua maneira de ver, as sociedades por ações, então em expansão por meio de novos mecanismos de crédito, eram formas de socialização da propriedade privada dentro dos marcos do capitalismo e, o que é mais importante, geravam novas condições para a apropriação da mais-valia. Em razão do aumento da participação dos capitais de terceiros na composição do capital total empregado na produção, uma parcela necessariamente maior da mais-valia precisava assumir a forma de juros

rendimentos extra-operacionais das empresas e da nova posição na hierarquia de suas direções do encarregado do financeiro, quanto os investimentos em fundos e carteiras e seus rendimentos na economia doméstica das famílias, inclusive uma parcela não desprezível da classe trabalhadora. 
para poder remunerar os donos desses capitais emprestados. Isso tem implicações importantes para a estabilidade e manutenção do sistema por seus efeitos sobre o consumo e o investimento, mas tem igualmente um significado muito forte em relação à forma como a natureza da economia capitalista pode ser percebida. Quando uma parcela expressiva da renda que dá direito à participação na riqueza social assume a forma de rendimentos financeiros, a criação do valor deixa de ser visível, o que tem repercussão até no meio das empresas, na exata medida em que ganhos extra-operacionais, trocas de ativos, jogadas na bolsa e outros negócios nos mercados financeiros proporcionam retornos maiores do que a atividade produtiva.

“[...] o juro aparece agora, ao contrário, como fruto do próprio capital, como original, e o lucro, agora na forma de ganho empresarial, como mero acessório aditivo que lhe advém no processo de reprodução. Aqui a figura fetichista do capital e a concepção do fetiche-capital está acabada. Em D - D' temos a forma irracional do capital, a inversão e a reificação das relações de produção em sua potência mais elevada [...] a capacidade do dinheiro [...] valorizar seu próprio valor, independentemente da reprodução - a mistificação do capital em sua forma mais crua” (Marx, 1990, t. 1, p. 294).

Em sua origem histórica, assim como foi compreendido por Marx, o capital é a forma da riqueza na sociedade capitalista e se constitui no conjunto de meios de produção (capital constante) e trabalho (capital variável) disponível em um certo momento e lugar. É o valor em estoque. A essa riqueza acumulada corresponde um conjunto de obrigações sociais na forma de títulos e certificados de propriedade que proporcionam a seu portador o acesso a seus benefícios, na forma dos rendimentos vinculados ao valor criado nos processos produtivos em que esse capital foi empregado. Da mesma maneira, há um fluxo de valor gerado pelo movimento desse estoque, que tem como contrapartida a circulação de moeda pela qual pode ser realizado no mercado.

Ora, o desenvolvimento e a crescente complexidade das relações capitalistas criaram condições para uma autonomia cada vez maior destes dois "outros" do trabalho produtivo. O "outro" do trabalho morto, acumulado, são os títulos de propriedade e o do trabalho vivo, a moeda em circulação; cada um deles tem essas representações virtuais como contrapartida fictícia e como fetiche, as quais desenvolvem movimentos próprios em sua esfera de ação específica. O descolamento dos movimentos autônomos desses signos dos estoques e fluxos do valor resulta em dois perigos potenciais para a estabilidade da acumulação capitalista, a especulação e a inflação.

Neste ponto, chegamos à dimensão monetária e financeira da crise. Marx descreveu os mecanismos do processo causador da superacumulção e da superprodução e ressaltou que sua existência tinha como pré-requisito a necessidade da troca por moeda para realização do valor. Em sua definição, a moeda gera a "possibilidade formal da crise" na medida em que separa, no tempo e no espaço, a 
compra e a venda, criando condições para que a mercadoria ou o trabalho não encontrem compradores enquanto o dinheiro preserva sua forma de riqueza líquida, quebrando-se assim toda uma cadeia de obrigações e expectativas relacionadas àquela produção.

"[...] the crisis derives its character not only from the unseleability of commodity, but from the non-fulfillment of a whole series of payments which depend on the sale of this particular commodity within this particular period of time. This is the characteristic form of money crisis" (Marx, 1863, part II, p. 514).

Ora, se a explicação de Marx ainda tem valia, qual a novidade do período recente? Uma primeira novidade é a duração do fenômeno de inchaço financeiro, vigente há mais de 20 anos. Essa perenidade num certo sentido justifica a defesa de Chesnais de um novo regime de acumulação. Entretanto, como lembra Braga (1997), se um colapso ainda não ocorreu, a exemplo de momentos semelhantes anteriores na história, também não há desenvolvimento, o que faz da financeirização um fenômeno histórica e socialmente limitado.

Pensamos que não é apenas o grau maior de complexidade das relações sociais que explica o impasse da crise contemporânea. Houve uma mudança qualitativa das instituições e, principalmente, do papel do Estado que impede uma resolução da crise por meio da depreciação do capital produtivo e, principalmente de sua contrapartida, do capital fixo, que desse margem a uma recuperação da taxa de lucro capaz de liderar um novo surto de crescimento sustentado. ${ }^{21}$

Impulsionado pelo retorno do liberalismo, o arranjo institucional que sustenta a política econômica mudou, tanto no plano nacional quanto no internacional. E o sentido da mudança está por trás do novo objetivo da política, a estabilidade em detrimento do crescimento. Os instrumentos anteriormente concebidos para coibir a especulação e condicionar a atividade financeira ao objetivo de alavancar a produção e o emprego - gasto público, tributação, intervenções do banco central e fixação da taxa de juros - passam a servir ao propósito de garantir e dar solvência aos mercados financeiros. Da mesma forma, o sistema internacional criado em Breton Woods e seus organismos multilaterais mudaram de função. De seu papel original, de compensar desequilíbrios nos balanços de pagamentos e fomentar o desenvolvimento, passou a, com apoio crescente do tesouro dos EUA, cumprir a missão de emprestador de última instância para a solvência dos mercados financeiros internacionalizados, por meio de seus pacotes de ajuda sempre acionados quando o risco de default se faz presente.

As garantias aparentemente infinitas dessa nova modalidade de regulação incentivam a ousadia dos agentes financeiros na criação de um volume cada vez

\footnotetext{
${ }^{21}$ Uma saída pela via da superação do capitalismo parece distante na medida em que não há o sujeito histórico capaz de realizá-la. A crise é também uma crise da classe trabalhadora e de sua política.
} 
maior de capital fictício. No entanto, há um limite, embora venha se mostrando extremamente elástico, dado pela relação entre o que é fetiche e o que é material, para o qual a mediação do Estado tornou-se decisiva. O crescimento da carga tributária, a mudança no perfil da despesa pública e o aumento do endividamento permitem ao Estado apropriar-se de uma parcela crescente da mais-valia na forma de imposto e arbitrar sua distribuição em favor da facção da classe capitalista detentora do "capital portador de juros". 22

De forma análoga, na relação entre os capitais privados, a criação e apropriação de capital fictício também implica uma redistribuição da mais-valia que, como foi visto acima, muda a modalidade da concorrência e opera uma restrição sobre a tendência à equalização da taxa de lucro. Essa relação já fora percebida por Marx quando analisou o crédito.

"O aproveitador do crédito, entretanto, fará descontar seus papagaios para expandir seu negócio, para cobrir um negócio podre pelo outro; não para fazer lucro, mas para obter a posse do capital alheio" (Marx, 1890, tomo 1, p. 323).

E isso porque, por meio dessa posse, terá acesso ao valor novo gerado pelo trabalho produtivo correspondente a esse capital ou, no caso dos títulos públicos, ao valor novo apropriado pelo Estado como receita tributária. Como a circulação financeira está internacionalizada, os devedores, tanto as empresas quanto os Estados, precisam desenvolver a capacidade de converter uma parte crescente de suas receitas em divisas de aceitação mundial, principalmente dólares.

As transformações no mundo do trabalho e da produção aqui abordadas, bem como a relação entre o capital produtivo e o capital improdutivo, especialmente o capital fictício, não só deram oportunidade a que discutíssemos aspectos que permaneceram e alguns que são novos na natureza do capitalismo, mas também deixaram perguntas em aberto. Por essa razão, talvez seja melhor apresentar, por conclusão, um conjunto de indagações com vistas ao futuro da pesquisa sobre o tema no campo da economia política de inspiração marxista.

Discutimos aqui o conceito de riqueza sob o capitalismo, desde sua noção mais evidente, um conjunto de bens materiais, até um conceito mais preciso, a posse do direito de ter acesso a um determinado padrão de bem-estar, um conjunto de privilégios sob este ponto de vista. A pergunta sobre o que vem a ser riqueza e o que vem a ser mercadoria faz sentido novamente e dá uma nova visão sobre a contradição entre capital produtivo e capital fictício. $\mathrm{O}$ valor na forma da moeda em circulação representaria um direito sobre o fluxo das mercadorias, seja materiais ou imateriais (serviços), enquanto a riqueza, na forma do capital fictício, um direi-

\footnotetext{
${ }^{22}$ A mudança no perfil da despesa pública, na medida em que representa uma substituição de gasto social por pagamento de juros ou subsídios ao capital, muda também a taxa de exploração, pois reduz a parcela do capital variável paga pelo Estado como salário indireto em saúde, educação, previdência etc. (Shaikh, 1978).
} 
to a um estoque desse valor acumulado (trabalho morto), representado pelos títulos em que se constitui.

Sob essa perspectiva, o desenvolvimento deve ser visto não apenas como um crescimento da riqueza, mas como desenvolvimento das relações de produção. Este ponto de vista decorre da relação entre as duas formas do valor referidas, os dois "outros" do trabalho produtivo, o valor como estoque e como fluxo. O primeiro caso corresponde ao que Marx chamou trabalho morto e o segundo, ao trabalho vivo.

Uma terceira questão está também vinculada à anterior e tem a ver com a atualidade da teoria do valor do trabalho. Decorre da mencionada polarização entre, de um lado, uma crescente complexidade do trabalho e, de outro, a perda de importância do trabalho vivo e da relação do valor novo criado com sua duração. Talvez uma retomada do debate entre Ricardo e Smith sobre trabalho incorporado e trabalho comandado fosse pertinente. No limite, se o objetivo é melhorar a qualidade de vida e o padrão de bem-estar das populações de maneira menos distorcida, a teoria do valor do trabalho deveria ser substituída não meramente por uma teoria do valor da informação, mas por uma teoria da importância da cidadania. Cidadãos do mundo todo, uni-vos!

Apesar de estarmos tentados a parar aqui, ainda há um último aspecto importante de ser mencionado, o qual diz respeito à forma como a hegemonia do capital portador de juros condiciona a política econômica. Mencionamos a onipresença do viés monetário com acento na estabilidade dos preços, cuja lógica está vinculada à preservação do valor na forma dinheiro. No entanto, para não deixar margem à dúvida da necessidade do vínculo com a forma produtiva do valor, é decisivo lembrar a inclinação "keynesiana" da política econômica dos EUA, aliás, dramaticamente retomada nos últimos dias, em que o objetivo central são o crescimento e o emprego. Faz parte do métier de líder mundial cuidar para que o descolamento entre os fluxos de valor e a circulação monetária e financeira não vá tão longe a ponto de provocar uma crise com suas conseqüências de desvalorização e destruição de capital ou para, pelo menos, sendo esta inevitável, poder minimamente direcionála para que, tanto quanto possível, possa beneficiar-se de seu desdobramento. Como diria o mais célebre filho de Pau Grande, ${ }^{23}$ fundamentalmente (ou seria “fundamentalisticamente”?), só falta mesmo combinar com os adversários.

\section{REFERÊNCIAS BIBLIOGRÁFICAS}

ARRIGHI, G. (1994). O longo século XX. Rio de Janeiro: Contraponto / São Paulo: Editora UNESP, 1996.

BELLUZZO, L. G. (1999). “Finança global e ciclos de expansão”. In: FIORI, J. L., org. (1999) Estados e moedas no desenvolvimento das nações. Petrópolis: Vozes.

${ }^{23}$ Garrincha, a "alegria do povo". 
BRAGA, J. C. (1997). "Financeirização global: o padrão sistêmico da riqueza no capitalismo contemporâneo". In: TAVARES, M. C. e FIORI, J., orgs. (1997).

BRAUDEL, F. (1979). Civilização material, economia e capitalismo: séculos XV-XVIII. São Paulo: Martins Fontes, 1996.

CHESNAIS, F. (1997a). "Mundialisação do capital, regime de acumulação predominantemente financeira e programa de ruptura com o neoliberalismo". Revista da Sociedade Brasileira de Economia Política. Rio de Janeiro: n. 1

CHESNAIS, F. (1997b). La mondialization du capital. Paris: Syros.

CHILCOTE, Edward B. (1997) "Inter-industry structure, relative prices, and productivity: an input-output study of the U.S. and the OECD countries". Ph.D. dissertation, New School for Social Research, New York.

MAGE, S. H. (1963). "The law of the falling tendency of the rate of profit: its place in the Marxian theoretical system and relevance to the United States", Ph.D. dissertation, Department of Economics, Columbia University, New York.

MARX, K. (1863). Theories of surplus-value. Moscou: Progress Publishers, 1978. (1864). El capital - Libro I, Capítulo VI (inédito). México: Siglo XXI, 1971. (1867). O capital: crítica da economia política. Livro I. São Paulo: Abril Cultural, 1983. (1890). O capital: crítica da economia política. Livro III. São Paulo: Abril Cultural, 1984.

MORRIS-SUZUKI, T. (1997). “Robots and capitalism”. In Davis, J., T. Hirschl and M. Stack, eds. Cutting edge: technology, information, capitalism and social revolution. London and New York: Verso.

SHAIKH, A. (1978). National income accounts and marxian categories. New York: New School for Social Research (mimeo.).

TAUILE, J. R. (2001). Para (re) construir o Brasil Contemporâneo. Rio de Janeiro: Contraponto.

TAUILE, J. R. e FARIA, L. (1999). “As transformações do capitalismo contemporâneo e sua natureza na análise de Marx". Revista de Economia Política, 19 (1), janeiro.

TAUILE, J. R., H. L. BORGES, A.A. PEREIRA e R.C. BRANCO (2001) "Excedente e mercadorias no capitalismo contemporâneo". Proposta, Ano 30, n. 88/89, FASE, Rio de Janeiro.

TAVARES, M. C. e FIORI, J., orgs. (1997). Poder e dinheiro: uma economia política da globalização. Petrópolis: Vozes. 